Цуркан А.А.

\title{
Агон как выражение принципа состязательности в античной традиции
}

Аннотация: Предметом данной статьи является феномен агона (принцип состязательности) в рамках античного культурно-исторического комплекса; его зависимость от античного архаического мифологического комплекса и особенности, возникшей на его основе олимпийской религии. Агональная традиция греко-римского мира как актуализация принципа состязательности в социокультурном процессе рассматривается в контексте социально-экономических и политических особенностей античной цивилизации, прежде всего, такой ключевой ее характеристики, как полисная модель общественной организации, сформировавшейся к VI веку до н.э. Методологической основой данной работы являются: метод восхождения от абстрактного к конкретному, принцип историзма, компаративистский анализ. Новизна и выводы данной статьи заключаются в следующем. Агон как актуализация принципа состязательности в греко-римской традиции стал возможен в силу специфики античного архаического мифа и олимпийской религии, которая заключается в отсутствии догматизированных норм и регламентаций поведения индивида, которые ограничивали его социальную активность. Комплекс герочческого ориентировал индивида на сверхусилие в свободной и честной конкуренции с целью достижения апофеоза. Отсутствие развитого танатологического аспекта способствовало усилиям индивида на достижение успеха в сфере имманентного.

Ключевъе слова: Агон, соперничество, архаический миф, герой, греко-римский мир, олимпийская религия, традиции, регламентация поведения индивида, догматизированные нормы, социальная активность.

Review: The subject of the present research article is the phenomenon of agon (competition principle) from the point of view of the culture-historical approach. In particular, the author studies the dependence of the competition principle on the ancient archaic mythology as well as peculiarities of the Olympic religion that had been created thereupon. As the implementation of the competition principle in socio-cultural environment, the Greco-Roman agon tradition is being viewed from the point of view of socio-economic and political peculiarities of the ancient civilization, first of all, the key feature - ancient city-states called polises that had been created by the VIth century. The methodological basis of the research includes the method of ascent from the abstract to the concrete, the historicism principle and comparative analysis. The novelty and conclusions of the research are the following. As the implementation of the competition principle, agon appeared in the Greco-Roman tradition due to the peculiar nature of the ancient archaic myth and Olympic religion that eliminated dogmatized standards and regulation of individual behavior and therefore any limits of social activity. The motif of becoming a hero encouraged an individual to put forth super efforts towards free and honest competition for the purpose of achieving apotheosis. The absence of a developed thanatological aspect made an individual to try to achieve success in the sphere of the immanent.

Keywords: Regulation of individual behavior, traditions, Olympic religion, Greco-Roman myth, hero, archaic myth, competition, agon, dogmatized standards, social activity.

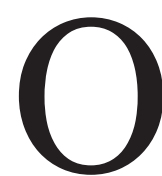

дним из наиболее ярких проявлений принципа состязательности как движущей силы социокультурно эволюции, несомненно, был античный агон. Возникновение агона как культурного и социально значимого феномена в Древней Греции сопряжено со становлением полисной цивилизации в VI веке до н.э., когда складываются ее фундаментальные характеристики. Явление полиса уникально, в особенности в сопоставлении с традициями более древними, в частности, в Египте и Месопотамии. Именно полисная цивилизация как социокультурный феномен и тип социально-политической организации способствовала возникновению того типа индивидуальности, который был мотивирован на достижение личного успеха, чего, фактически, мы не находим в традициях древневосточных цивилизаций. Данная социально-психологическая установка, 
в конечном итоге, продуцирует явление под названием «агон». Исторически агоном [греч. ' $\alpha \gamma \omega v$, борьба, состязание] называлась у греков любая борьба или состязание, но главным образом агонами обозначались игры, происходившие по поводу религиозных или политических празднеств.

Состязательность, в широком смысле слова, проникает в контекст всего многообразия культурных явлений в жизни древнегреческих городов-государств. Имеющиеся в современном историческом антиковедении источники, в особенности касающиеся жизни Афин VI-IV вв. до н.э. позволяют с высокой степенью достоверности и убедительности утверждать, что вне контекста состязательности в жизни древнегреческих городов-государств фактически мы не находим сколь-нибудь значимого аспекта или сферы. Это касается не только сугубо спортивной активности в тех ее проявлениях, которые всем хорошо известны (в частности, Олимпийские, Пифийские, Немейские игры), но и в таких, казалось бы, далеких от спорта областях деятельности человека, как искусство, политика и даже интеллектуальная деятельность (философия).

«Состязание, во всем, при каждом удобном случае, стало для греков столь интенсивной функцией культуры, что его принимали за «обычную» и полноценную золотую монету» [1. С. 44]. «Агон постоянно присутствует и в мифе, и в эпосе: агон мирный и боевой.<..> эллин сравнительно легко переступает грань, отделявшую его от богов, порой отваживаясь даже бросать вызов небожителям, недвусмысленно приглашая их к единоборству» [2. С. 84]. Именно в полисе с его замкнутой территорией и ограниченным числом граждан, которые в большинстве своем могли знать друг друга, общественное признание должно быть особенно ощутимым при первых же успехах творческой деятельности человека. На это указывают Платон [Законы, V, 737d -738 е] и Аристотель [Политика,VII, 1326b 14-19].

Вместе с тем, стоит иметь в виду, что хотя полис как корпорация свободных граждан, объединенных перед лицом внутренней угрозы со стороны рабов и внешней опасности со стороны соседей (чаще всего, не эллинов) и был той социально-полити- ческой матрицей, в рамках которой развивалась агональная традиция Древней Греции и Рима, истоки этого явления стоит искать глубже, в специфике архаического мифа Греции, того мифологического субстрата, который лежит в основе всей греческой культуры. В последней миф понимался как "... бытие $\Omega$ и ч н о с или, точнее, образ бытия личностного, личностная форма, $\Omega$ и $л и$ чн о с $m u »$ [3. C.115]. Дело в том, что установка на достижение личного успеха и общественного признания, с точки зрения социальной психологии, может быть оценена как прямой результат тех особенностей, которые мы обнаруживаем в контексте греческого мифологического сознания, прежде всего в части, касающейся восприятия времени, жизненного пространства человека, феномена смерти и посмертного существования человеческой души.

Как известно, греческая мифологическая традиция в этом смысле отличается от ближневосточной, в частности, иудейской тем, что не дает человеку надежды на сколь-нибудь позитивную перспективу загробного существования. «Царство Аида», как оно рисуется в эпической поэзии Греции, в частности, в произведениях Гомера и Гесиода - это область минимальной интенсивности бытия, когда тень человека, удерживающая его индивидуальные черты и характеристики, фактически останавливается в своей активности и оказывается обречена на бесконечно долгое существование в подземном царстве, без сколь-нибудь видимой надежды на улучшение качества своего бытия. Здесь нет и намека на спасение и райское существование, которое является вожделенной целью для любого смертного, скажем, в библейской традиции. «Острова блаженных» зарезервированы за героями и выдающимися личностями, которые проявили себя наиболее ярко и в этом смысле могут быть оценены как своеобразная аналогия тому, что мы находим в библейской традиции в связи с описание «райского блаженства». Само их наличие, как области посмертного существования, предназначенного для избранных и выдающихся людей, говорит о том, что уже в рамках архаического мифа Древней Греции существует определенного рода психологическая установка на 
то, чтобы индивид стремился к обретению этого выдающегося статуса как залога посмертного блаженного существования. Чем менее значимы достижения индивида в земной деятельности, чем менее выдающимся в глазах своих современников и потомков он оказывается, тем более вероятна для него перспектива забвения в «царстве Аида». И напротив, если индивид в свободной и честной конкуренции c себе подобными проявляет наиболее выдающимся образом лучшие свои качества, тем самым доказывая окружающим свое право на общественное признание, милость богов и перспективу оказаться на «островах блаженных, где управляют сыновья Зевса - Минос и Радамант, оно оказывается той вожделенной наградой триумфатору, ради которой, собственно, стоит и жить на Земле.

Широчайший масштаб реализации принципа агонистики в греко-римской традиции был бы вряд ли возможен без того мировоззренческого контекста, в рамках которого этот принцип развивался. Речь идет, прежде всего, о парадигме религиозного сознания в Греции и Риме, о том религиозно-мифологическом субстрате, в рамках которого формировались основные черты и характеристики античной культуры. С точки зрения мировоззренческой ценности и важности олимпийская религия греков, возникшая на основе архаического мифологического субстрата, предлагает нам такую модель религиозности, в рамках которой мы видим ряд существенных характеристик, отличающих эту модель от иудео-христианской традиции. Попытаемся дать оценку этим характеристикам, исходя из того, насколько они влияли на самосознание индивида, насколько они мотивировали его к активному действию в свободной конкуренции с себе подобными.

Стоит иметь в виду, что оценка олимпийской религии в отечественной традиции чаще всего была довольно негативной. В научной, философской литературе неоднократно отмечался формальный характер греко-римской религии, а также то обстоятельство, что она была частью светской полисной культуры, неким сакральным флёром, который греко-римское сознание набрасывало на социально-значимый праксис, на рукотворные нормы правовой и моральной сфер. С учетом известных своих предпочтений крупнейший отечественный знаток античной философии и, в частности, платонизма А.Ф. Лосев не сумел воздержаться от довольно броской, если не провокативной тирады в отношении греческой религии. В частности, в своем фундаментальном произведении «История Античной эстетики» он заявляет: Религия, в которой нет мистики, нет таинства, нет догматов, нет всего аппарата грехопадений и искуплений, всевозможных смертей и воскресений, слез и рыданий, суда, мук и пр., то есть религия, которая попросту является только моралью, такая религия, очевидно, не только вполне безвредна для мещанства, но оно специально выдумывает для себя такую религию» [4. С.406].

В этом пассаже мы видим основные характеристики греко-римского религиозного сознания: нарочитую светскость последнего, условность религиозных норм и довольно свободный, неформальный характер отправления культа. В совокупности эти характеристики позволяли индивиду чувствовать себя довольно свободно в отношениях с богами. Поскольку категория «божественного», схваченная интуитивно и воплощенная в знаковосимволических и эстетических формах и проявлениях, воспринималась эллинским сознанием иначе, чем в ближневосточной традиции, здесь, прежде всего, бросается в глаза то обстоятельство, что олимпийская религия не содержит сколь-нибудь жестких норм, постулатов, догматов, заповедей, которые регулировали бы жизнь человека от его рождения до смерти и сообщали его сознанию устойчивые установки, которые мы в избытке находим в иудео-христианской традиции. Речь идет о комплексах вины, греха и нечистой совести.

Отсутствие догматики и священных текстов, открытость жречества к пополнению за счет систематического вхождения в коллегию жрецов представителей народа в самом широком смысле этого слова, отправление культа, которое воспринималось как часть социально-политической деятельности, общественное служение - все это, в совокупности, несомненно, позволяло избежать того прессинга регламентации и наставлений, которые ку- 
пировали бы естественный импульс состязательности и тормозили социальноэкономические и политическое развитие античного общества, пойдя оно по пути древневосточных цивилизаций. В результате отсутствие этого прессинга не только обеспечило комфортные условия для реализации принципа состязательности, но и побуждало индивида к тому, чтобы он осуществлял этот принцип в возможно более широких масштабах. Оценка божественного в контексте олимпийской peлигии, как мы видим это на протяжении почти всей греческой истории, далека от тех мистико-метафизических истолкований божества, которые присутствуют в таких мощных философских традициях как пифагореизм и платонизм.

Стоит иметь в виду, что античная философия не была магистральным духовным явлением для греко-римского общества. Она была, скорее, уделом подавляющего меньшинства, маргинальной формой культуры для интеллектуалов. Основной же массив свободного населения греческих полисов, а затем и Римской республики, находился всецело в лоне религиозномифологических представлений, сформировавшихся в древнейшую эпоху и овеществленных в рамках государственной религии, каковой, фактически, и была система олимпийского культа. Оценка богов в рамках последнего исходила из того, что божественное - это синоним могущества, силы, величия, в котором эстетическая составляющая всегда превалировала над этической. Олимпийские боги не давали смертным никаких наставлений и заповедей. Более того, их поведение часто копировало поведение простых смертных, и в этом смысле в качестве объекта для поклонения олимпийцы воспринимались сознанием обывателя скорее эстетически, нежели чем этически. Они не любили людей и не требовали в ответ от человека какой бы то ни было любви. Максимум того, что они могли ожидать от смертных - это уважение в отношении к их величию.

Сам же индивид в своих отношениях с божественным пребывал практически всегда в состоянии, которое побуждало его копировать образцы поведения олимпийцев, состязаться с ними для того, чтобы в максимально возможной степени уподобиться их могуществу, величию и силе. Отсутствие значимой дифференциации между телом и душой, высокий статус свободного гражданина, по крайней мере, в классическую эпоху, как в истории Греции так и Рима, исключали саму возможность для человека квалифицировать себя как «раб божий». Эта самооценка, как известно, является фундаментальной для иудаизма, христианства и ислама - трех авраамических религий. Немыслимость восприятия себя как раба в отношении олимпийских богов при всем при том, что смертный отдавал себе отчет в том, что олимпийцы превосходят его могуществом и силой, прямо отражает высокий коэффициент гражданского самосознания в античном обществе. Это делает человека гордым, свободным и достойным, что не могло не повлиять на реализацию принципа состязательности. «Человек смотрит в лицо богов спокойно как вполне совершенная личность, во всем подобная статуям самих богов. Это - тот род свободы и духовности, который приобретается ценой безопасности и доверия. Но реальность налагает свои ограничения даже и на свободного человека: боги есть и остаются «сильными мира сего»» [5. С.189].

Поскольку греческая религия не являлась источником сакральной нравственной нормы, как мы находим это, например, в Ветхом завете, в рамках иудейской традиции, это, с необходимостью, влекло за собой широчайшие возможности для индивида, выступающего в роли свободного гражданина создавать самостоятельно нормы конвенциональной этики и закреплять их в столь же конвенциональных правовых положениях и законах. Это открывало перспективу самореализации в самом широком смысле этого слова, поскольку конвенциональная мораль или право активно подвергались переработке и не воспринимались сознанием гражданина как раз и навсегда данное и неизменное. Все это создавало дополнительные предпосылки для активной вовлеченности человека в социально-политическую деятельность с целью максимально широкой реализации. Данная ситуация не могла не повлиять, в качестве мощного стимула, на развитие состязательного процесса в Античности во всех его формах и проявлениях. 
В философской литературе очень часто можно встретить точку зрения, согласно которой в лучший период своей истории, т.е. от Гомера до Перикла, греки были закоренелыми пессимистами. Вся их культура несла на себе печать безнадежного трагизма. Обзор существующих по этому поводу точек зрения содержится в замечательной монографии А.И. Зайцева «Культурный переворот в Древней Греции VIII-V вв. до н.э.» [6. С.67-90]. Однако, не смотря на присутствующие в античной литературе этого периода нотки пессимизма трудно предположить, что эта точка зрения является истинной. Еще труднее говорить о диктате пессимистического мироощущения в отношении греческой культуры эпохи классики. Поскольку народ, который состоял бы из закоренелых пессимистов, вряд ли создал бы такой фантастический тип культуры как это сделали греки. Греки вряд ли были бы способны на безудержное проявление своей креативности в самых разных областях, совокупность которых составляет фундамент всей европейской цивилизации. Речь идет как о гражданском и политическом строительстве, так и о проявлении греческого гения в области эстетики, что трудно переоценить.

Тема «отчаяния», которая время от времени находит свое проявление в культуре эллинов этого периода, тем не менее, должна быть признана сопутствующей и часто откровенно вторичной в отношении гораздо более значимой темы, а именно темы героического стремления индивида к самореализации, в борьбе за жизненный успех, славу и счастье. Переживая довольно болезненно свое онтологическое одиночество в мире, где царит слепой и неведомый рок, в равной мере господствующий как над смертными, так и над бессмертными, грек, тем не менее, стремился к возможно большей независимости от этих грозных и непостижимых сил, часто враждебных по отношению к человеку.

И в классическую, и в архаическую эпоху грек находил опору в себе самом, в своем понимании миссии человека на этой земле, в героическом усилии по преодолению тех трудностей, с которыми смертные сталкиваются с необходимостью ради достижения возможно большего уподобления богам, в идеале - апофеоза, т.е. пря- мого обожествления смертного, как мы это находим в мифологическом и религиозном контекстах (классический пример - «Подвиги Геракла»), так и в историческую эпоху (в частности, в образе Александра Великого и, отнюдь не только его). Это было особое отношение к жизни, которое можно назвать своеобразной разновидностью трагического героизма, когда осознание смертности и конечности человеческого бытия, запечатлённое в мироощущении олимпийской религии, не только не парализует воли человека к сопротивлению в отношении самой жизни, но и побуждает его активно менять эту жизнь, достигая успеха, славы и общественного признания и запечатлевая свое имя в памяти потомков.

В конечном итоге, это не могло не способствовать активнейшей реализации принципа агона в греко-римской традиции. Спокойное отношение к смерти, которое мы находим в греко-римской религии, приятие ее как естественного хода вещей, отсутствие невротической установки в отношении достижения вечной жизни и сколь-нибудь выраженного фанатизма на этот счет, свойственного авраамическим религиям, быть может, было продиктовано эстетическим, геометрическим чувством меры, свойственным греческому сознанию на всех уровнях его эволюции. Именно это обстоятельство сообщало религиозному сознанию греко-римского мира тот оттенок пессимизма, который часто подчеркивается исследователями, оценивающими феномен греко-римского сознания с позиции христианских, либо квази христианских.

Психологическая основа этой своеобразной дисциплины сознания, коренящаяся в эстетически оформленной интуиции телесности, геометричности того мироздания, которое греки пытались актуализировать по ходу развития своей культуры, их стремление к гармонии во всем, чтобы они не делали и, несомненно, уважение к интеллекту и статусу самого человека, которое мы находим особенно явно в классическую эпоху, ограничивали эксцессы религиозного фанатизма и делали сознание греков чрезвычайно взвешенным и эффективным в реализации тех стремлений, которые индивид оценивал как значимые для себя, смысл образу- 
ющие. Обостренное чувство гражданской свободы и человеческого достоинства, осознание своих прав как чисто личностных, так и гражданских, купировало импульсы религиозного фанатизма в культурной истории греко-римского мира.

Все это делало возможным для индивида пусть и трагедийное, но, тем не менее, вполне позитивное мироощущение. Оно стимулировало развитие греко-римской цивилизации на протяжении того периода, который предшествовал утверждению христианства в качестве господствующей духовной силы умиравшей Римской империи. Как хорошо высказался на эту тему английский историк А. Циммерн: «Греки сидели за жизненным столом честно и прямо, не ожидая никакого десерта» [7. C.325] в виде посмертного воздаяния, адских мук или райского блаженства. Этот имманентный характер их сознания, установка на самореализацию «здесь и сейчас» в сфере земного, в плоскости человеческих отношений - все это не могло не способствовать актуализации принципа агона в греко-римской традиции.

Таким образом, земная активность индивида, с точки зрения мифологической традиции греко-римского мира оказывается весьма значимой, в особенности в сопоставлении с ближневосточной, в частности, библейской интерпретацией категории времени. В рамках последней время оценивается как синоним страдания и ожидания загробного наказания, либо воздаяния. В греческой же традиции перспектива «вечного блаженства» носит вполне ощутимый телесный характер и не сопряжена с интенсивной внутренней духовноочистительной деятельностью, как мы это обнаруживаем в рамках библейской мифологии. От человека требуется экспликация его лучших качеств, которые имели бы социальную значимость и ценностно-смысловое наполнение в глазах окружающих. Именно поэтому «... оценка коллектива, к которому принадлежал человек (и более узкого и более широкого) была важнейшим регулятором поведения индивида во всех его конкретных проявлениях, а отнюдь не только в плане выработки общих жизненных принципов» [6. C.113].

Человек в рамках греческого архаического мифа мотивирован не на духовную эволюцию ради обретения «райского блаженства», а на зримое, вполне ощутимое достижение успеха в своей активности. Әто соответствует базовой характеристике не только греческой мифологии, но и культуры в целом. Данную характеристику мы находим, в частности, у А.Ф. Лосева. Ученый высказывается об античном типе культуры как о предельной обобщенности «... природно-человеческой телесности в ее нераздельности с ее специфически жизненным назначением» [8. С.220]. Акцент на социально-значимой актуализации успешности индивида как в рамках архаического мифа, так и в историческую эпоху здесь является разительным контрастом в отношении того примата внутреннего духовного опыта и преображения, который мы находим в иудео-христианской традиции с древнейших времен вплоть до сегодняшнего дня.

И в мифологическую и в историческую эпохи эта установка способствовала тому, чтобы человек стремился в земной, социально-значимой практике выразить с наибольшей степенью убедительности те свои достоинства, которые, в сопоставлении с аналогичными чертами других участников социального процесса, обеспечили бы ему общественное признание и память потомков. Именно память потомков оказывается своеобразного рода фиксацией в сознании эллина и римлянина и может быть оценена как компенсация отсутствия того самого внутреннего духовного опыта мистико-религиозного преображения, который присущ древневосточным peлигиозно-мифологическим комплексам. Пожалуй, это наиболее надежное условие обретения вечности, пусть и в превращенной форме.

Память потомков является гораздо более надежной, с точки зрения эллина и римлянина, формой обретения вечной жизни, нежели чем мистическое преображение и спасение души в загробном мире, как это происходит на Древнем Востоке. Именно этим обстоятельством объясняется тот беспрецедентный по своему значению факт, что любой свободный эллин и римлянин так тщательно старался сохранить свое имя, равно как имена и даже облик своих предков. В частности, в римской традиции это находит свое проявление в обычае, имевшем древнейшее про- 
исхождение, украшать дома изображениями умерших предков.

Стремление зафиксировать в сознании потомков свое имя и деяния с помощью различных приемов (в частности, через увековечивание памяти в монументах, надписях и т.д.) свидетельствует о том, что эллин и римлянин воспринимал время весьма обостренно. Для него было значимо то обстоятельство, что человек вовлечен в жизненный процесс. Греко-римское сознание отдавало себе отчет в быстротечности времени. И тому мы находим немало подтверждений. Именно эта установка так разительно отличается от спокойного созерцания временного процесса, которое мы находим в рамках восточной традиции вплоть до сегодняшнего дня.

Интенсивность жизненного процесса в купе с быстротечностью времени подталкивали индивида как в мифологическую, так и в историческую эпоху в Греции и Риме к тому, чтобы он использовал довольно короткий жизненный цикл для того, чтобы максимально возможным образом запечатлеть себя в памяти потомков, с одной стороны, и добиться наибольшего признания в глазах современников - с другой. Агон как фундаментальное явление греко-римской культуры был лишен стихийного характера. Чаще всего состязательность была организована по определенным правилам и в соответствии с определенными нормами, имевшими ценностно-смысловой статус в глазах участников социального процесса. И хотя состязательность выходит за рамки тех соревнований, которые чаще всего упоминаются в связи с присутствием этого принципа в греко-римской традиции (речь идет, прежде всего, об олимпийской традиции) и пронизывает все аспекты социальной жизни древнего грека и римлянина, тем не менее, общий для античной цивилизации акцент на упорядочивание реальности находит свое значимое проявление и в этой области.

Поскольку nomos как принцип упорядоченности и геометричности социально-политического бытия, основой которого является закон, воспринимался греко-римским сознанием как базовая ценность и подлинная основа политической жизни - этот подход находит свое проявление и в организации состяза- тельного процесса. Одна из главных отличительных особенностей организации состязательного процесса в греко-римском историческом пространстве как раз и заключается в том, что главенствующие интуиции греко-римского сознания гармония, мера и соразмерность как три составляющих красоты по Аристотелю, геометрическая структура Космоса как макро реальности, будучи спроецирована на социально-политический процесс, придают последнему импульс упорядоченности и геометричности. В свою очередь, это обеспечивает высокую степень прозрачности правил конкуренции в самых различных сферах социокультурной эволюции греко-римского мира.

Представляется в высшей степени не случайным то обстоятельство, что агон затухает в первые века н.э. и сходит на нет в эпоху христианского европейского Средневековья. Однако он оказывается реанимирован, восстановлен в своих правах, превращается в весьма значимый фактор новоевропейского социокультурного процесса как раз в связи с ревизией консервативной модели христианского сознания, которая ассоциируется с Римско-католической церковью. Появление протестантских деноминаций христианства в эпоху Нового времени, приобретших весьма значимый характер и статус в контексте европейского общественного сознания и культуры, со свойственной им установкой на достижение видимого и признаваемого сообществом успеха здесь, в сфере имманентного, как раз и является той причиной, по которой состязательность оказывается вновь восстановленной в своих правах.

Ревизия христианской мифологии в контексте протестантского религиозного сознания требует от индивида овеществления его талантов, фактического подтверждения своего земного статуса как своеобразного признания близости к божеству. Успехи в бизнесе и труде отождествляются с сакральной молитвенной практикой. От человека ожидают успешного карьерного роста и достижения таких результатов в своем деле, которые имели бы общественное признание и высокий ценностно-смысловой статус. Все это в значительной мере коррелирует с той дохристианской установкой, которая 
свойственна греческому языческому сознанию и восходит к отмеченному нами выше мифологическому комплексу - apхаическому мифу Эллады и Рима. Имманентный характер олимпийской религии формирует в Античности ту общественно-значимую установку, которая диктует индивиду необходимость овеществления своих талантов. Именно это обстоятельство, свойственное всей греко-римской традиции, и обеспечивает агону ту степень воздействия на общественное сознание и социальную практику, которая на выходе дает потрясающие результаты практически во всех областях культурной деятельности греко-римского мира.

Подводя итог, можно заметить следующее. Состязательность как базовый принцип социокультурной эволюции и его манифестация в контексте греко-римского культурно-исторического комплекса, несомненно, имеют ключевое значение для понимания специфики социокультурной эволюции Европы с древнейших времен вплоть до сегодняшнего дня. Не отрицая значимость социально-экономических и политических форм, в рамках которых реализуется агон в контексте греко-рим- ской культуры, ни коем образом не сомневаясь в воздействии этих базисных характеристик греко-римского общества, прежде всего, демократии и классического рабовладения на поведение индивида в социуме, тем не менее, мы склонны признать, что главенствующей причиной, которая позволила сформировать агон как ключевую характеристику греко-римской культуры являлся архаический миф. Речь идет о мифологическом комплексе, со свойственной ему ориентацией индивида на самореализацию в сфере имманентного (героизм), с целью достижения общественно-значимого результата, который не типичен для христианского религиозно-мифологического сознания и в значительной мере составляет специфику политеистической религиозности.

В истории Европы понадобилось около восьми столетий, чтобы этот принцип, эта экзистенциально-психологическая установка были восстановлены в своих правах и обеспечивали, в конечном итоге, мощнейший импульс социально-экономического, политического и духовного развития европейцев в эпоху Нового и Новейшего времени.

\section{Библиография:}

1. Хёйзинга Й. Хomo Ludens / Человек играющий. Статьи по истории культуры / Й.Хёйзинга // Пер. с нидерландского и сост. Д.В. Сильвестрова. - М.: Айрис-пресс, 2003. - 496 с.

2. Шанин Ю.В. Олимпия. История античного атлетизма / Ю.В. Шанин. - СПб.: Алетейя, 2001. - 191 с.

3. Лосев А.Ф. Диалектика мифа / А.Ф. Лосев. - СПб.: Азбука, Азбука-Аттикус, 2014. - 320 с.

4. Лосев А.Ф. История Античной эстетики. Итоги тысячелетнего развития / А.Ф. Лосев. - В двух книгах. Кн. 2. - М.: «АCТ», 1994. -608 c.

5. Буккерт В. Греческая религия: архаика и классика / В. Буккерт. - Пер с нем. М. Витковской и В. Витковского. - СПб.: Алетейя, 2004. - 535 с.

6. Зайцев А.И. Культурный переворот в Древней Греции VIII-V вв. до н.э. / А.И. Зайцев // Под ред. Л.Я. Жмудя. - 2-е изд., испр. и перераб. - СПб: Филологический факультет СПбГУ, 2001. - 320 с.

7. Андреев Ю.В. Цена свободы и гармонии: несколько штрихов к портрету греческой цивилизации / Ю.В. Андреев. - СПб.: Алетейя, 1998. - 200 с.

8. Лосев А.Ф. Философия культуры / А.Ф. Лосев. Дерзание духа. - М.: Политиздат, 1988. - С. 218-237.

\section{References (transliterated):}

1. Kheizinga I. Xomo Ludens / Chelovek igrayushchii. Stat'i po istorii kul'-tury / I.Kheizinga // Per. s niderlandskogo i sost. D.V. Sil'vestrova. - M.: Airis-press, 2003. - 496 s.

2. Shanin Yu.V. Olimpiya. Istoriya antichnogo atletizma / Yu.V. Shanin. - SPb.: Aleteiya, 2001. - $191 \mathrm{~s}$.

3. Losev A.F. Dialektika mifa / A.F. Losev. - SPb.: Azbuka, Azbuka-Attikus, 2014. - 320 s.

4. Losev A.F. Istoriya Antichnoi estetiki. Itogi tysyacheletnego razvitiya / A.F. Losev. - V dvukh knigakh. - Kn. 2. - M.: «AST», 1994. - 608 s. 


\section{Культура и искусство 1(31) • 2016}

5. Bukkert V. Grecheskaya religiya: arkhaika i klassika / V. Bukkert. - Per s nem. M. Vitkovskoi i V. Vitkovskogo. - SPb.: Aleteiya, 2004. - $535 \mathrm{~s}$.

6. Zaitsev A.I. Kul'turnyi perevorot v Drevnei Gretsii VIII-V vv. do n.e. / A.I. Zaitsev // Pod red. L.Ya. Zhmudya. - 2-e izd., ispr. i pererab. - SPb: Filologicheskii fakul'tet SPbGU, 2001. - 320 s.

7. Andreev Yu.V. Tsena svobody i garmonii: neskol'ko shtrikhov k portretu grecheskoi tsivilizatsii / Yu.V. Andreev. - SPb.: Aleteiya, 1998. - $200 \mathrm{~s}$.

8. Losev A.F. Filosofiya kul’tury / A.F. Losev. Derzanie dukha. - M.: Politizdat, 1988. - S. 218-237. 